IRA-International Journal of Applied Sciences ISSN 2455-4499; Vol.04, Issue 01 (2016)

Institute of Research Advances

http://research-advances.org/index.php/IRAJAS

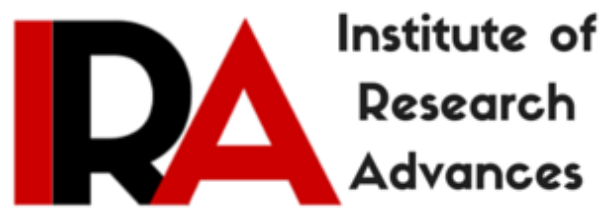

\title{
Phytomedicine - A Holistic Approach in Dentistry
}

\author{
Dr. Rita Zarina MDS $^{1}$, Dr. Jaini. J. L MDS $^{2}$, Dr. Ektah Khosla MDS ${ }^{3}$. \\ ${ }^{1}$ Professor and Head, Department of Pedodontics and Preventive Dentistry, \\ Govt. Dental College, Kottayam, Kerala, India. \\ ${ }^{2}$ Reader, Department of Prosthodontics, Amrita School of Dentistry, Kochi, \\ Kerala, India. \\ ${ }^{3}$ Professor, Department of Pedodontics and Preventive Dentistry, Mar Baselious \\ Dental College, Thankalam, Kothamangalam, Kerala.
}

DOI: http://dx.doi.org/10.21013/jas.v4.n1.p9

\section{How to cite this paper:}

Zarina, R., J. L, J., \& Khosla, E. (2016). Phytomedicine - A Holistic Approach in Dentistry. IRA-International Journal of Applied Sciences (ISSN 2455-4499), 4(1). doi:http://dx.doi.org/10.21013/jas.v4.n1.p9

(C) Institute of Research Advances

(c)) EY-NC

This works is licensed under a Creative Commons Attribution-Non Commercial 4.0 International License subject to proper citation to the publication source of the work.

Disclaimer: The scholarly papers as reviewed and published by the Institute of Research Advances (IRA) are the views and opinions of their respective authors and are not the views or opinions of the IRA. The IRA disclaims of any harm or loss caused due to the published content to any party. 


\section{ABSTRACT}

Herbal products have been used since ancient times in folk medicine, involving both eastern and western medicinal traditions. Many plants with biological and anti-microbiological properties have been studied since there has been a relevant increase in the incidence of antibiotic overuse and misuse. In dentistry Phytomedicines has been used as anti-inflammatory, antibiotic, analgesic and sedative agents. This paper highlights certain medicinal plant which is used in dentistry as alternative and in holistic way.

Key words: Phytomedicin, medicinal plants, microbial disease, antimicrobial agents

\section{Introduction}

In developing countries, infectious disease represents an important cause of mortality among populations. Although many new antimicrobial agents were developed in last decade, resistance has become a global problem. Moreover, most serious threat to successful treatment of microbial disease is the spread of drug resistant pathogens. As people are becoming aware of side effects of synthetic drugs and resistant pathogens, there is an urgent need to develop novel antimicrobial agents.

As global scenario is now changing holistically, the use of non-toxic and eco-friendly products, development of modern drugs from traditional medicinal plants should be emphasized for the control of various human pathogens.Medicinal plants have been used as traditional treatments for numerous human diseases for thousands of years and in many parts of the world.Drug made from these plant products have advantage of being simple, effective and exhibit broad spectrum activity [1] Medicinal plant products when compare to their synthetic counterparts minimize the adverse side effects [2,3]. A lot of research has been carried out on the utilization of medicinal plants in the treatment of a variety of oral diseases.Therefore, this article highlights certain medicinal plant extracts or phytochemicals that are effective in dental diseases.

\section{Various Herbals}

\section{Azadirachtaindica(Neem)}

Neem is popular because of its analgesic, anti-inflammatory, antifungal and immune regulatory action .In dentistry neem is investigated because of its antimicrobial potential against oral microorganisms associated with gingivitis and periodontitis [4]. Anti adherence property by altering bacterial adhesion make it an alternative to other mouthwashes. Neem is also used as endodontic irrigant against E.faecalis [5].

\section{Ocimum sanctum (Tulsi)}

A small herb seen throughout India, regarded as queen of herb because of its popular medicinal and mythological value. Its leaves are chewed to maintain oral hygiene. Carracrol and Tetpene are the antibacterial agents present in this plant. It also contains sesquiterpene b-caryophyllene which has similar action. Tulsi act as COX2 inhibitor due to its significant amount of eugenol(1-hydroxyl-2 methoxy-4 allyl benzene) [5]. It is also reported that $4 \%$ tulsi extract has maximum antimicrobial activity against S.Mutans which indicates its anticaries activity. Because of its essential oil and its main components (eugenol and linalool) tulsi also has antifungal activity against C.albicans $[6,7]$

\section{Morindacitrifolia(Noni)}

It is also called as Indian Mulberry. Its juice has therapeutic effects including antibacterial, antiinflammatory, antiviral, antitumor, antihelmenthic, analgesic, hypotensive, anti-inflammatory and immune enhancing effects. Morinda Citrifolia juice is used as an endodontic irrigant which is more biocompatible than sodium hypochlorite [8]. 


\section{ArctiumLappa}

Arctiumlappa is a plant which is widely used in popular medicine all over the world for its well-known therapeutic applications. It has anti-bacterial and antifungal, diuretic, anti-oxidan, anxiolytic action, platelet anti-aggregating effect and HIV- inhibitory action. In dentistry, Arctiumlappa has been investigated due to its antimicrobial potential against oral microorganisms, specifically those associated with endodontic infections $[9,10]$.

\section{Triphala}

Triphala is a traditional ayurvedic herbal formulation consisting of Amulaki (emblicaofficinalis), Bibhitaki (terminaliabellirica) and Halituki (terminalia chebula).Conditions for which Triphala is employed include headache, dyspepsia, constipation, liver conditions, ascites and leucorrhoea. It is also used as a blood purifier and got anti-inflammatory, analgesic, anti-arthritic, hypoglycemic and anti-aging properties [11]. T. chebula which acts as anti caries agents and strengthens the gums, prevents and treats several diseases of mouth such as dental caries, spongy and bleeding gums gingivitis and stomatitis. Its fruit is rich in citric acid, which may aid in removal of smear layer thereby acting as chelating agent and also found to be alternative to sodium hypochlorite for root canal irrigation $[11,12]$.

\section{Garlic(Allium sativum)}

The main active component of garlic is allicin. It has antibacterial immune regulatory functions. Allicin destroys cell wall and cell membrane of root canal bacteria, so this can be used as intra canal irrigant $[13,14]$.

\section{Sanguinariacanadensis(Blood root)}

Chemically, sanguinarine is a benzophenanthridine alkaloid derived from the alcoholic extraction of powdered rhizomes of the bloodroot plant, Sanguinaria Canadensis. Sanguinarine contains the chemically reactive iminium ion which is probably responsible for its activity. It is proved that sanguinarine at a concentration of 16 microgram permilliliter completely inhibit $98 \%$ of microbial isolates from human dental plaque and that sanguinarine and zinc act synergistically in suppressing the growth of various oral strains of streptococci [15]. Research has shown that the alkaloid is retained in the mouth for long periods after brushing, providing longer resistance to plaque and gingival inflammation [16].

\section{Green tea}

It is a tea made solely from the leaves of camellia sinensis. Green tea is particularly rich in healthpromoting flavonoids (which account for $30 \%$ of the dry weight of a leaf), including catechins and their derivatives. The most abundant catechin in green tea is epigallocatechin-3-gallate, which is thought to play an important role in the green tea's anticancer and antioxidant effects. It has been suggested that green tea also promotes periodontal health by reducing inflammation, preventing bone resorption and limiting the growth of certain bacteria associated with periodontal diseases. It is also found to be a good chelating agent. Intake of green tea can stop degenerative changes by inhibiting the action of the reactive oxygen species molecule $[17,18]$.

\section{Licorice root}

Licorice is the name applied to the roots and stolons of Glycyrrhiza species. Licorice root sextract contains Glycyrrhizol A, a compound that has strong antimicrobial activity against cariogenic bacteria. Studies showed that a brief application of Licoriceroots extract in lollipop led to a marked reduction of cariogenic bacteria in oral cavity amongmost human $[19,20]$.

\section{Psidiumguajava (Myrtaceae)}

The paste of tender leaves of Psidiumguajava has been used traditionally to maintain oral hygiene, while other parts of the plant have various bioactive properties. A methanol extract of P. guajava leaves was shown to exhibit inhibitory activity against two strains of $S$. mutan. The fruits and leaves contain essential 
oil rich in cineol, tannins, tripentnes and flavinoids. Ethanol extracts of it has higher antimicrobial activity, especially against E-faecalis [21].

\section{Turmeric (Circuma longa)}

It is a perennial plant with orange, oblog tubers. Dried turmeric powder has got antioxidant, antiinflammatory and antimutagenic actions. It is proved that turmeric got anti cariogenic action against $S$. Mutans. Mouthwashes are prepared because of its anti-inflammatory and antimicrobial action $[22,23]$.

\section{Tender coconut Water (CocosNucifera)}

In Sanskrit, the coconut palm is known as Kalpa Vriksha, meaning "tree which gives all that is necessary for living," since nearly all parts of the tree can be used in some manner or another. Coconut water contains a blend of vitamins, minerals, amino acids, carbohydrates, antioxidants, enzymes, health enhancing growth hormones and other phyto-nutrients. Because its electrolyte content is similar to human plasma, it is used as natural sports drink for oral dehydration. Unlike other beverages, it is completely compatible with the human body, in so much that it can be infused directly into the bloodstream. Other use include oral rehydration, enhances immune function, possesses anti-aging properties, decreased swelling, relieve spasm, root canal irrigant (antiviral, antifungal and antimicrobial properties) and storage media for avulsed tooth $[24,25,26]$.

\section{Orange oil}

Orange oil produced by glands inside the rind ofan orange fruit. This is composed mostly of dlimonene. It also has long chain aliphatichydrocarbon alcohols, aldehydes like octanal and can be used as an alternative tochloroform or xylene for gutta-percha softening and also in dissolving endodontic sealers $[27,28]$.

\section{Aloebarbadensis (Aloevera)}

This herb posses anti-inflammatory, anti-bacterial, anti-fungal,anti-viral,wound healing properties. The peptidase bradykinase was isolated from aloe and shown to break down the bradykinin, an inflammatory substance that induces pain. Streptoccocuspyogenes and Streptococcus faecalisare two microorganisms that have been inhibited by aloevera gel. It has also got antioxidant effects and free radical scavenger activity. The gel from aloe vera is used to treat apthous ulcer, lichen planus, herpes infection etc [29,30].

\section{German chamomil (Marticariarecutitia L.)}

It is an annual plant, native to Europe and Western Asia, and is used in parts of the world as a table tea. It is in fact the flower of the chamomile plant, which contains a wide variety of active chemical components, which are thought to be responsible for many of its medicinal applications. German Chamomilehas been used for centuries as a medicinal plant mostly for its anti-inflammatory, analgesic, anti-microbial, anti spasmic and sedative, antibacterial and bacteriostatic action. It has been used in combination with other herbal ingredients as mouth wash or dentifrice to reduce plaque growth and to improve the gingival health. Its extract promotes wound healing by decreasing the inflammatory responses and accelerating granulation and regeneration of the tissues on topical application [31,32].

\section{Punicagranatum (Pomegranate)}

Pomegranate seeds are a source of many nutrients and they can also be used for medicinal purpose. Punicalagin is a major antioxidant polyphenol in pomegranate juice. It has got antibacterial and antimicrobial activity, effective against methicillin-sensitive and resistant S.aureus,E.coli,S.typhy,C.albicans and some streptococcus strains(S.mutan,S.mitis) [32]. The antibacterial agents in Pomegranate-hydrolysable tannins- form complexes of high molecular weight with soluble proteins, increase bacterial lysis and interfere with bacterial adherence to tooth surfaces. The antiinflammatory effect is due to its immune regulatory activity over macrophages and $\mathrm{T}$ and $\mathrm{B}$ lymphocyte subsets $[33,34]$. 


\section{Grape Seed Extract}

Grape seed extract contains proanthocyanidins which are potent antioxidants and are known to possess anti-inflammatory, antibacterial and immune-stimulating effects. It has been reported to strengthen collagen based tissues by increasing collagen cross-links. In a study conducted to determine remineralizing effects of grape seed extract on artificial root caries, results showed that is a promising natural agent for non-invasive root caries therapy [35,36]

\section{Propolis}

This is prepared from resins collected by bees from trees of poplars and conifers or from flowers of genera clusia. It also contains viscidone. Mainlyuse as intracanal medicaments, root canal irrigant and storage media for avulsed teeth to maintain viability of periodontal ligament cells $[37,38]$.

\section{Cayenne (Capsium annum)}

Cyenne has an antiseptic action, since its constituents show antimicrobial effects against certain Clostridium, Streptococcus, and Bacillus organisms, as well as bactericidal activity against Helicobacter pylori. Cayenne also contains the dark-red pigment capsanthin, as well as other carotenoid which may enhance immune function. Topical application of capsicum extract used to treat herpes zoster, recurrent apthous stomatitis [39]

\section{Papaine}

Papaine is a proteolytic enzyme that extracted from the latex of the leaves and fruits of the green adult papaya. It has an anti-inflammatory, bacteriostatic, bactericidal action and is effective against gram positive and gram negative organisms. Similar to human pepsin, papaine acts as a chemical debridement anti-inflammatory agent, which does not damage healthy tissues and accelerates cicatrization process [40]. Papaine acts only in infected tissue as it lacks a plasmatic antiprotease called a-1-anti-trypsin. The absence of this enzyme in infected tissues allows papaine to break the partially degraded collagen molecules only, contributing to the degradation and elimination of fibrin "mantle" formed by carious process [41].

\section{Clove(Sysygiumaromatium)}

It is popularly used as a spice with potent antiseptic, stimulant and antiemetic action. Clove oil is used for gum and teeth pain from ancient times. It is also used to prevent halitosis. Eugenol in clove essential oil has analgesic and antiseptic properties. The eugenol and other constituents of clove, such as vanillin and iso-eugenol, have also been reported to have antimicrobial effect [42].

\section{Conclusion}

There is a long and venerable history of the use of plants to improve dental health and promote oral hygiene. Plant contain phytochemicals such as alkaloids, tannins, essential oils and flavanoids which have pronounced defensive and curative activity.. A single herb may show a variety of effects like antiinflammatory, antibacterial, antifungal activity and many more. Hence the incorporation of these herbs in dental practice will prove to be a valuable adjunct in dental treatment.But there is minimum information about quality, safety and greater efficiency of these products for use in dentistry. As most of the studies are carried out ex vivo, more of these compounds should be subjected to animal and human studies to determine their effectiveness, side effects, toxicity and drug interactions.

\section{References}

1.Bapuji, JL., and Ratnam, SV.(2009). Traditional uses of some medicinal plants by tribals of GangarajuMadugulaMandal of Visakhapatnam district, Andhra Pradesh. Ethnobotanical Leaflets, 13:38898. 
2. Kanwar, P., Sharma, N., and Rekha, A. (2006). Medicinal plants use in traditional healthcare systems prevalent in Western Himalayas. Indian Journal of Traditional Knowledge, 5:300-9.

3. Little, JW. (2004). Complementary and alternative medicine: impact on dentistry. Oral Surg Oral Med Oral Pathol Oral RadiolEndod, 98(2):137-145.

4.Subapriya, R., and Nagini, S. (2005). Medicinal properties of neem leaves: a review. Curr Med Chem Anticancer Agents, 5(2): 149-146.

5.Ganguli, S. (2002). Neem: A therapeutic for all seasons Current Science, 82: 1304.

6.Bhateja, Sumitetal. (2012). Therapeutic benefits of holy Basil(Tulsi) in general and oral medicine-A review, JRAP3(6)Nov-Dec 2012.

7. Agarwal, P., Nagesh, and L., Muralikrishnan. (2010). Evaluation of the antimicrobial activity of various concentration of Tulsi extract against streptococcus mutan.Ind J Dent Res, 21(3):357-58.

8. Murray, PE., Farber, RM., Namerow, KN., Kuttler, S., and Garcia-Godoy F. (2008) Evaluation of Morindacitrifolia as an endodontic irrigant. J Endod., 34(1): 66-70.

9.Pereira, JV., Bergamo, DC., Pereira, JO., FrançaSde, C., Pietro, RC., and Silva-Sousa YT. (2005). Antimicrobial activity of Arctiumlappa constituents against microorganisms commonly found in endodontic infections. BrazDent J., 16(3): 192-196.

10.Gentil, M., Pereira, JV., Pietro, R., Sousa Neto, MD., Vansan, LP., and FrancaSd . (2006). In vitro evaluation of the antibacterial activity of Arctiumlappa as a phytotherapeutic agent used in intracanal dressings Phytothera.Res, 20: 184-86.

11. Anne, McIntyre. (2005). Herbal treatment of children: Western and Ayurvedic perspectives. Elsevier Health Sciences, 278-280.

12. Prabhakar, J., Senthilkumar, M., Priya, M S., Mahalakshmi, K., Sehgal, PK., Sukumaran, VG. (2010). Evaluation of antimicrobial efficacy of herbal alternatives (Triphala and Green tea polyphenols),MTAD and 5\% sodium hypochloride againstEnterococcus faecalis biofilm formed on tooth substrate: An invitro study. J Endod, 36: 83-86.

13. Traditional Chinese medicine used in root canal disinfection research. Pharmacy papers (Online article). http:/ /eng.hi138.com/?b106.

14. Lawson, LD., and R. Bauer. (1998). Garlic: A Review of its Medicinal Effects and Indicated Active Compounds. Phytomedicines of Europe: Chemistry and Biological Activity. Washington, DC: American Chemical Society Symposium Series 691. Pg. 176-209.

15. Cullinan, M.P., Powell, R.N., Faddy, M.J., and Seymour, G.J. (1997). Efficacy of a dentifrice and oral rinse containingSanguinaria extract in conjunction with initial periodontal therapy. Australian Dental Journal, 42(1): 47-51.

16.Arnason, J.T., Guerin, B., and Kraml, M.M., [and others]. (1992). Phototoxic and photochemical properties of sanguinarine. Photochemistry and Photobiology. 55(1): 35-38.

17. Yu, H., Oho, T., Tagomori, S., and Morioka, T,. (1992). Anticariogenic effects of green tea. Fukuoka IgakuZasshi, 83:174-80.

18.Sakanaka, S., Aizawa, M., Kim, M., and Yamamoto, T. (1996). Inhibitory effects of green tea polyphenols on growth and cellular adherence of an oral bacterium, Porphyromonasgingivalis. Biosci Biotech Biochem, 60:745-9.

19. Messier, C., Epifano, F., Genovese, S., and Grenier, D. ( 2012). Licorice and its potential beneficial effects in common oro-dental diseases. Oral Dis.,18(1):32-39.

20.Touyz, LZ. (2009). Liquorice health check, Oro-dental implications, and a case report. Case Report Med, 170735.

21. Sanches, NR., Cortez, DAG., Schiavini, MS., Nakamura, CV., and Filho, BPD. (2005). An evaluation of antibacterial activities of Psidiumguajava.Braz Arch BiolTechnol, 48: 429-430. 
22. Chaturvedi, TP. (2009). Uses of turmeric in dentistry in dentistry -an update. Indian J Dent Res, 20(1): 107-109.

23.Rathaur, P., Raja, W., Ramteke, PW., and JohnSA.(2012). Turmeric,the golden spice of life.IJPSR, 3(7):1987-94

24. Gopikrishna, V., Thomas, T., and Kandaswamy D.(208). A quantitative analysis of coconut water: a new storage media for avulsed teeth. Oral Surg Oral Med Oral Pathol Oral RadiolEndod.,105(2): e61-65.

25. Moreira-Neto, JJ., Gondim, JO., Raddi, MS., and Pansani, CA. (2009). Viability of human fibroblasts in coconut water as a storage medium. IntEndod J.,42(9): 827-830.

26. Gopikrishna, V., Baweja, PS., Venkateshbabu, N., Thomas, T., and Kandaswamy, D. Comparison of coconut water, propolis, HBSS, and milk on PDL cell survival.. J Endod., 2008; 34(5): 587-589.

27. Bauer, K., Garbe, D., and Surburg, H. (2001) . Common Fragrence and Flavor Materials, 4th Ed, Wiley VCH :189.

28.Mushtaq, M., Masoodi, A., Farooq, R., and Yaqoob khan, F. (2012). The dissolving ability of different organic solvents on three root canal sealants-invitro study. Iran Endod J. 7(4)198-202 .

29. Maguire, H., Torbinejad, M., and Kettering, JD. (1996). Use of aloe vera gel as an intracanal medicament.J Endod, 22(4): 193.

30. Wynn, RL. (2005). Aloe Vera gel: update for dentistry ,general dentistry, 53(1): 6-9.

31. Lahijani, MSS., Kateb, HRR., Heady, and R., Yazdan, D. (2006). The effect of German chamomile (Marticariarecutita L.) extract and tea tree (Melaleucaalternifolia L.) oil used as irrigants on removal of smear layer: a scanning electron microscopy study. International Endodontic Journal, 39: 190-195.

32. Singh, O., Khanam, Z., Misra, N., and Srivastava, MK. (2011). Chamomile (Matricariachamomilla L.): An overview. Pharmacogn Rev., 5(9): 82-95.

33. Van der Ouderra, F J. (1991). Antiplaque agents:Rational and prospects for prevention of gingivitis and periodontal diseases. J Clin Periodontology, 18:447-454.

34. Menezes, S M., Cordeiro, L N,. and Viana, G S. (2006). Punicagrantum(pomegranate) extract isactive against dental plaque.J Herb pharmacother, 6:79-92.

35. Wu, CD. (2009). Grape products and oral health. J Nutr., 139(9):1818S-1823S.

36.Xie, Q., Bedran-Russo, AK., and Wu, CD. (2008). In vitro remineralization effects of grape seed extract on artificial root caries. J Dent., 36(11): 900-906.

37. Oncag, A., Cogulu, D., Uzel, A., and Sorkun, K. (2006). Efficacy of propolisas an intracanal medicament against EnerococcusfaecalisGen. Dent, 54: 319-22.

38. Martin, MP., and Pileggi, R. (2004). A quantitative analysis of Propolis: a promising new storage media following avulsion. Dent Traumatol, 20: 85-9.

39. Christopher., and Dr. John, R. (1999). School of Natural Healing, (11th printing), Christopher Publ., Utah, pg. 447-449.

40. Bussadori, SK., Castro LC., and Galvão, AC. (2005). Papain gel: a new chemo-mechanical caries removal agent. J ClinPediatr Dent, 30(2):115-119.

41. Bertassoni, LE., and Marshall, GW. (2009). Papain-gel degrades intact non mineralized type I collagen fibrils. Scanning,31(6): 253-258.

42. Moon SE., Kim HY., and Cha JD.(2011). Synergistic effect between clove oil and its major compounds and antibiotics against oral bacteria. Arch Oral Biol., 56(9): 907-916. 